use of this drug, to increase its concentration in the urine.

Dyes of the pyridine series have recently been employed as urinary antiseptics. They also can be used without negard to the reaction of the urine, and it is claimed that they can penetrate the walls of the tract and so exert an antiseptic action in the tissues. The flavine series have been used by mouth, intravenously, and for local irrigations. They liave the advantage that their action is not impaired by the presence of serum. Euflavine is probably the best of the group, the urine being made alkaline with sodium bicarbonate. In chronic cases a succession of such remedies can be tried. Attention must be directed to possible foci of reinfection, and any factor which may cause stasis or retention must be dealt with. In certain cases, as in pregnancy, the indwelling ureteral catheter is of temporary advantage.

\section{The Ketogenic Diet}

The observation that the urine of diabetics with acidosis and of epileptics under the ketogenic diet did not readily become infected suggested the use of this type of diet in cases of urinary infection. To produce the appearince of ketone bodies in the urine a very strict dietary control is essential. The diet contains large quantities of fat, and the carbohydrate has to be restricted to between 20 and 30 grams. After a few days on this strict regime acetone bodies begin to appear in the urine, and the $p \mathrm{H}$ may fall to about 5 . Tested on a group of chronic cases which had resisted all other forms of treatment, this method proved successful in about one-half the patients, the infection clearing up in remarkable fashion in some of the cases. ${ }^{25}$ The ketogenic diet is unappetising and even nauseating, and it is difficult to get patients to co-operate thoroughly for any length of time. It is unlikely that this method of treatment will be much used except in the most resistant cases.

\section{Biliary Infections}

The effects of treatment in lesions of the biliary tract can be less easily observed than in the case of the renal system. During the acute phase general measures must be taken against pain and fever. For chronic infections, where surgery is not indicated, other medical methods may be tried. As in the case of the urinary tract, an effort should be made to flush the system. A copious intake of fluid may be helpful in producing a free flow of bile. Drainage of the gall-bladder and biliary passages may be regularly undertaken by introducing concentrated magnesium sulphate through a tube in the duodenum. Specimens of the bile can be withdrawiı and examined bacteriologically if care be taken to avoid contamination, but the results so obtained are not very reliable. Hurst ${ }^{14}$ finds that magnesium sulphate by mouth (without the tube) is just as efficient. He gives each morning the largest dose of a concentrated solution which the patient can take without being purged. The action may be further enhanced by an injection of pituitrin a quarter of an hour before taking the Epsom salts. Half an ounce of olive oil before meals may stimulate a flow in the same way. Treatment can be reinforced by the administration of sodium salicylate or hexamine; the salicylate is an efficient cholagogue. Hexamine reaches the bile, and is frequently prescribed in conditions of the gall-bladder, but as the medium is alkaline it is difficult to see how it can act. Hurst says that it can clear up an infection in a few days.

In $B$. coti septicaemia a search should be made for a focus of infection which may be constantly passing organisms into the circulation. Intravenous medications are of doubtful value. Mercurochrome has been most often given, but it is not without danger.

\section{REFERENCES}

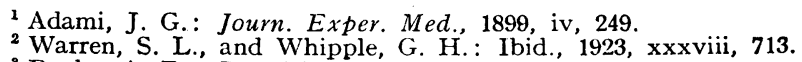

s Rooke, A. R.: Practitioner, 1925, cxv, 205.

Walker, K. M.: Lancet, 1930, i, 681.

- Nabarro, D.: British Medical Journal, 1930, ii, 414

6 David, V. C., and McGill, E. C.: Journ. Urol., 1923, x, 223.

Helmholz, H. F., and Milliken, F.: Amer. Journ. Dis. Child., 1922, xxiii, 309 .

${ }^{8}$ Barrington, F. J. F., and Wright, H. D.: Journ. Path. and Bact., 1930, xxxiii, 871.

9 Book, M. H.: Amer. Journ. Path., 1933, ix, 569.
10 Moody, W. B., and Irons, E. E.: Journ. Infect. Dis., 1923,

xxxii, 226.
Thiele, F. H., and Embleton, D.: Proc. Roy. Soc. Med., 1914, iii, 69.

${ }_{12}$ Cameron, H. C.: Guy's Hospital Reports, 1932, lxxxii, 390.

13 Lepper, E. H.: Journ. Path. and Bact., 1921, xxiv, 192.

14 Hurst, A. F.: Guy's Hospital Reports, 1932, lxxxii, 396.

15 Williams, B., and McLachlan, D. G. S. : Lancet, 1930, ii, 342.

${ }^{16}$ Baird, D.: Edinburgh Obstet. Soc. Rep., 1934, p. 69.

17 Alvarez, W. C.: Physiological Review, 1924, iv, 353.

18 Redeuill, F. H., et al.: Journ. Amer. Med. Assoc., 1930, xciv, 688.

${ }^{19}$ Cowie, D. M., and Hicks, W. C.: Journ. Lab. and Clin. Med., 1931-2, xvii, 681 .

${ }^{20}$ Weinberg, M., and Prévot, A. R.: C. R. Soc. de Biol., 1933, cxiii, 1029.

${ }^{21}$ Vincent, H.: Amer. Journ. Med. Sci., 1932, clxxxiii, 301.

${ }^{22}$ Helmholz, H. F.: Brit. Journ. Child. Dis., 1929, xxvi, 247.

${ }^{23}$ Ryle, J. A.: Guy's Hospital Reports, 1932, lxxxii, 339.

${ }^{24}$ Stockman, R.: Edin. Med. Journ., 1927, xxxiv, 396.

${ }_{25}$ Band, D., Dunlop, I). M., and Dick, I. L.: Proc. Roy. Soc. Med., 1933, xxvi, 217.

${ }^{20}$ Wilkinson, K. D.: British Medical Journal, 1930, ii, 412.

\section{CONDITIONS PREDISPOSING TO B. COLI INFECTION AFTER POST-OPERATIVE RETENTION *

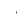 \\ BY}

CUTHBERT DUKES, M.Sc., M.D.'

PATHOLOGIST, ST. PETER'S HOSPITAL; DIRECTOR OF RESEARCH LABORATORY, ST. MARK'S HOSPITAL

The $B$. coli infections of the urinary tract which follow post-operative retention can be studied with a completeness which is not possible in sporadic infections. Tests can be carried out before the operation to find if the urinary organs are healthy, and periodic examinations during convalescence will show at what time and in what circumstances the urine becomes infected. The observer is in the fortunate position of knowing when the patient will be exposed to the risk of infection:, he can look for common factors in those who succumb and those who escape.

During the last six years I have had the opportunity of making daily observations on 214 cases of retention of urine following the operation of excision of the rectum for cancer. This operation does not open or directly damage the urinary tract, but like other extensive pelvic operations it disturbs the nervous mechanism of micturition, necessitating catheterization usually for three or four days. In many of these cases urinary sepsis supervenes, the infection being attributable either to instrumentation or to a lymphatic or haematogenous infection from the operation wound. Other patients escape infection. We are discussing the aetiology of $B$. coli infections to-day, and my contribution consists in a demonstration of those conditions which predispose to infection when the function of the bladder is temporarily deranged after surgical operations.

\section{Incidence of Infection}

It will help towards an understanding of the question if before describing the factors which predispose to infection in this type of case I mention some which do not

* Read in opening a discussion in the Section of Medicine at the Annual Meeting of the British Medical Association, Bournemouth, 1934. 
affect the frequency of urinary infections. Changes in nursing personmel, for instance, made no difference to the proportion of urinary infections, and the incidence was approximately the same in each ward of the hospital. It was natural to look into this question because the women patients were all catheterized by sisters and senior nurses. Retention in men patients was relieved by an indwelling catheter with an antiseptic seal, ${ }^{1}$ and the fact that only a small proportion of the men patients became infected is a tribute to the good quality of the nursing at St. Mark's Hospital. If less care had been taken with the sterilization and passage of catheters there would no doubt have been a higher proportion of infection. Similarly, it was found that the incidence of infection was approximately the same in the practice of each of the six surgeons on the staff of the hospital, and did not vary in the three operations commonly performed for iancer of the rectum-namely, perineal, abdominoFerineal, and perineo-abdominal excision.

It was also interesting to notice that minor defects in renal function, such as are accompanied by a rise in the blood urea to 50 or $60 \mathrm{mg}$. or a fall in the van Slyke urea clearance test to $\mathbf{4 0}$ or $\mathbf{5 0}$ per cent. did not predispose to urinary infection: there was no greater frequency of infection in the group showing these defects compared with other patients whose renal function tests before operation were more satisfactory. More severe defects in renal function would probably have predisposed to urinary infection, but such cases were not accepted as operable.

\section{Causative Factors}

Turning to the factors which influence the frequency of urinary infections, much the most obvious is sex. Infections following post-operative retention are much commoner in women than in men. In the whole series

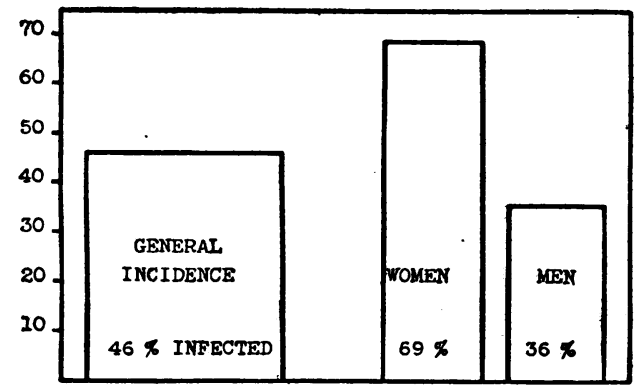

FIG. 1.-Infection following post-operative retention of urine. Incidence in each sex.

of 214 patients, $B$. coli infection developed in ninety-nine (46 per cent.). Infection occurred in forty-seven out of sixty-eight women (69 per cent.), but in only fifty-two out of 146 men (36 per cent.) (see Fig. 1). This higher incidence of infection in women is not unexpected when one considers the difficulty of catheterization in a woman helpless after an extensive pelvic operation. In these circumstances the urine generally becomes infected within twenty-four hours of the commencement of catheterization, and pyuria supervenes two or three days later. In men patients, drained by a self-retaining catheter with an antiseptic seal, it is possible to keep the urine sterile and free from pus for several days. Thus, during the last few years nearly 100 men patients have had a catheter tied in for three to six days without any infection other than a slight urethritis.

Next to sex the most important factor predisposing to urinary infection is old age. The risk of infection increases steadily with advancing years both in women and in men. Of the women under 60 only 62 per cent. became infected after post-operative retention, but in those over
60, 86 per cent. developed $B$. coli infections. Similarly with the men-only 28 per cent. of those under 60 became infected, compared with 47 per cent. of those over this age (Fig. 2). This increased frequency of urinary infections in elderly subjects is attributable in women patients chiefly to loss of muscle tone, and in men to the increasing incidence of prostatic disease. Both these influences result in a longer period of retention, and as a general rule the longer the period of retention the greater the risk of infection."

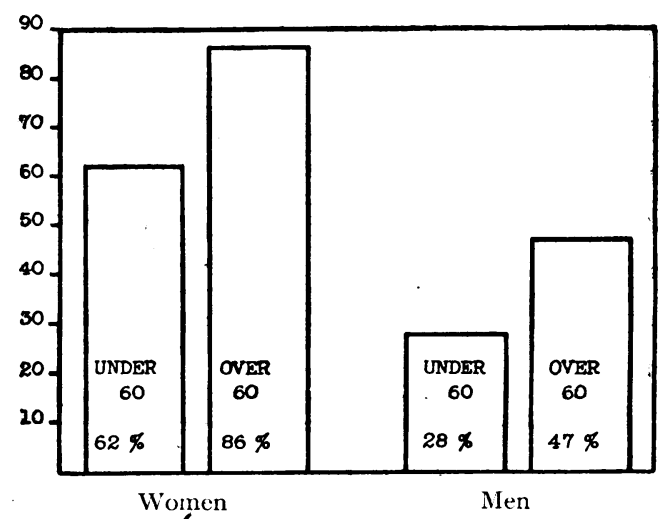

FIG. 2.-Influence of age in liability to infection in postoperative retention of urine.

The relation of the period of retention to likelihood of infection is shown by the fact that in men who suffered from retention for more than three days 38 per cent. became infected, but only 15 per cent. of infections occurred among those whose retention lasted a shorter

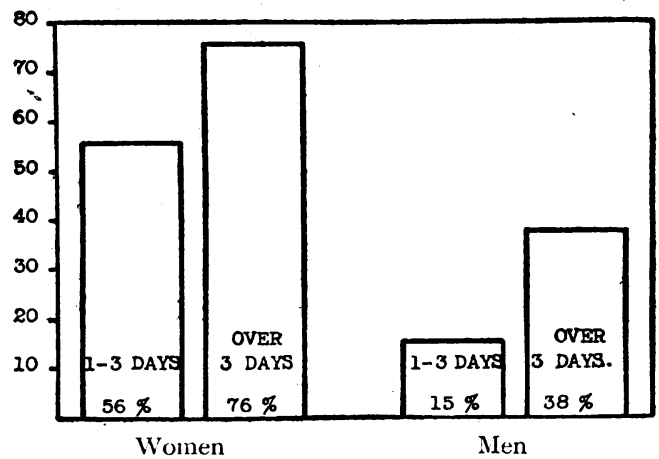

FIG. 3.-Influence of duration of retention of urine in liability to infection.

period. Similarly with the women-infections occurred in 76 per cent. of those requiring catheterization for more than three days, and in only 56 per cent. of those with retention lasting less than three days (Fig. 3).

\section{Discussion}

Finally, it is possible to show from this analysis that the patient's general state of health is an important factor in the incidence of urinary infection after post-operative retention. All the patients on whom these observations have been made had undergone the operation of excision of the rectum for cancer. In the early stages of this disease the general health is not impaired, but when the growth has ulcerated extensively and commenced to invade the extrarectal tissues there is a serious decline in the patient's general condition. Early cases are thus in a much better state of health at the time of operation than late cases. The lowered vitality is reflected in the increased incidence of generalized sepsis, and the higher operative mortality rate in the " $C$ " group of cases, in which the glands contain metastases. ${ }^{34}$ 
The influence of the stage of the cancer on the risk of urinary infection is shown by the fact that among women 77 per cent. of the late cases became infected and only 59 per cent. of the early cases. Similarly, among men infections occurred in 42 per cent. of the late cases and in only 32 per cent. of the early cases (Fig. 4). The average age in each group was approximately the same, and it seems justifiable to attribute the increased incidence of urinary infection in the more advanced cases of cancer to a decline in general health.

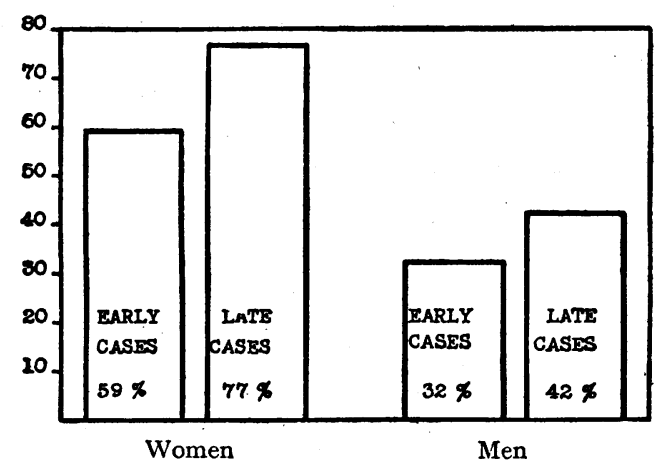

FIg. 4.-Influence of the patient's general condition as shown by the frequency of post-operative urinary infections in early and late cases of cancer of the rectum.

These four factors-sex, age, duration of retention, and general health-are each responsible for considerable variation from the average in the incidence of $B$. coli infections after post-operative retention. The last three are to some extent dependent on each other, the duration of the retention being related to the age group and also to the patient's general state of health. Moreover, although for descriptive purposes. these four factors have been considered separately, it must be pointed out, in conclusion, that they all predispose to infection because of their influence on the functional activity of the bladder. From the point of view of the subject under discussion their main interest lies in the fact that they exemplify a principle, familiar in urinary pathology but not always so easy to demonstrate in detail, that urinary infections are often dependent on defective function of the urinary organs.

REFERENCES

${ }^{1}$ Dukes, C.: Proc. Roy. Soc. Med., December, 1928, vol. xxii, Section of Surgery, Subsection of Proctology, p. 1.

Idem: Ibid., May, 1932, Section of Surgery and Urology, p. 1828

s Idem: Journ. Path. and Bact., 1932, xxxv, 323

- Gabriel, W. B.: Brit. Journ. Surg., 1932, xx, 234

The creation of new slum areas by smoke-polluted atmosphere is to receive special consideration at the annual conference of the National Smoke Abatement Society, which will be held at Glasgow from September 27th to 29th. Dr. J. Johnstone Jervis, medical officer of health for Leeds, will be the chief speaker on the subject of slum clearance and smoke prevention. Dr. $\mathrm{J}$. S. Owens, who is in charge of the investigations into atmospheric pollution on behalf of the Department of Scientific and Industrial Research, and has invented many of the delicate instruments used for the measurement of atmospheric pollution, is to describe the latest developments in this direction. New instruments for the measurement of smoke emission will also be demonstrated. Special consideration is to be given to the effects of smoke upon visibility and aviation, and upon horticulture. The delegates will be given a civic reception by the Lord Provost in the City Chambers, and the discussions will take place in the Council Hall. The chairmen at the :arious sessions will include Dr. H. A. Des Vœux, president of the society, and Dr. John R. Currie, professor of public health at Glasgow University.

\section{THE VALUE OF RADIOLOGY (DIAGNOSIS AND TREATMENT) AS AN AID TO THE GENERAL PRACTITIONER*}

BY

\author{
J. H. DOUGLAS WEBSTER, M.D., F.R.C.P.ED. \\ PHYSICIAN IN CHARGE OF THE RADIOLOGY DEPARTMENT, \\ MIDDLISEX HOSPITAL
}

The three specialties-surgery, radiology, and pathologyhave both a technical and a medical side, and have had eminent exponents of one or both aspects. Radiology occupies a position midway between the other two: it is in many ways ancillary, as pathology and bacteriology are (from the practitioner's point of view), while in other ways it is more independent, as the surgical specialties are. Again, the radiologist can rarely diagnose or treat " at a distance," as is the custom of the pathologist and the bacteriologist. The presence of the patient is usually as essential to him as it is to the surgeon. Radiology is therefore more a clinical specialty than a laboratory specialty.

Some of the more outstanding pioneers in the subject have been better known as biologists than as technicians. Some years ago Sir John Bland-Sutton, in speaking of members of his own craft, drew attention to this distinction, and few will deny that radiologists will be more likely to rise high in scientific reputation and in usefulness to their colleagues and the community when they regard themselves primarily as physicians-physicians who practise in radiology-than when they consider themselves only, or essentially, as technicians. In so far as they take their proper place as medical consultants rather than as technical consultants they will face far greater difficulties, and will have many opportunities, too, for exercising tact, both with patients and with their colleagues, but their value and general usefulness will in time be much greater.

\section{Value of a Diagnostic or Therapeutic Method}

The value of a diagnostic method is established by its affording evidence which can throw new light on obscure clinical problems, and still more when it can afford signs of such high value as evidence that they can be called pathognomonic. Radiology, it has been said with much truth, has brought forward a far greater number of such pathognomonic signs in its short existence than all the previous centuries of clinical observation could accumulate. In ancient medicine, and well on into the Middle Ages, physicians found, as they thought, infallible diagnostic and prognostic signs in astrological calculations or "images" (Chaucer): the position of the stars at the time of onset of the illness was generally agreed to be pathognomonic. Magic in diagnosis is less popular now, but in treatment, radium-to the public at large, and even to some members of the profession-has undoubtedly magical properties. The more scientific and less magical bases of diagnosis and prognosis began early in clinical observation, and later on progressed as the study of physical signs grew in accuracy. Thus in auscultation as a method we have relative and absolute examples of value in the discovery of a mitral systolic murmur, which can have one of many different interpretations, as compared with that of the presystolic murmur of mitral stenosis (crescendo, and heard supine). While some radiological authorities, such as Köhler, regard the value of radiological diagnostic evidence as always relative and quite secondary to clinical findings, I rather agree with

* Read in opening a discussion in the Section of Radiology and Electrotherapeutics at the Annual Meeting of the British Medical Association,. Bournemouth, 1934. 